\title{
Creating Healthy Enterprises: the Workplace Health Action Plan in China
}

\author{
Yanyan Sun'; Xin Sun ${ }^{1}$; Jun Ren ${ }^{1, *}$; Boya $\operatorname{Li}^{1}$
}

\section{Summary}

On October 21, 2019, the "Notice on promoting the healthy enterprises" and "Specification of Healthy Enterprise Construction (trial)" were issued jointly by the National Patriotic Health Campaign Committee Office and six other government partners. As one of the objectives and tasks of the occupational health protection action (2019-2030), this multisectoral "Healthy Enterprise" Action Plan (HEAP) serves as the first "healthy cell" project carried out at the national level as an indispensable part of the Healthy China Initiative and the Healthy City Movement.

It is of great significance to recognize the importance of the burden of disease linked to the exposure of occupational risks and the ability to identify the main areas of concern.

This article interprets the process of how the healthy workplace or healthy enterprise was originated and evolved; how the theory was introduced and developed in China; and how the 4 main action indicators toward healthier and safer workplaces were formulated including the following: 1) developing the health policy system; 2) building healthy working environments; 3) providing health services; and 4) creating healthy culture. It concludes that the national "healthy enterprise" policy is a specific workplace-based public health practice in the field of occupational health and contributes to build a preventive culture in the context of the Healthy China Initiative. It aims to explore and summarize workplace health promotion models, methods, and experience suitable for China and to disseminate them across China.

\section{BACKGROUND OF THE HEALTHY ENTERPRISE ACTION PLAN}

In 1995, the World Health Assembly of the World Health Organization (WHO) endorsed the Global Strategy on Occupational Health for All, which emphasized the importance of primary prevention of occupational diseases and encouraged countries to establish national policies and programs for occupational health (1). However, 10 years later, a national survey revealed that improvements in healthy workplace approaches were minimal and that further improvement was required (2). In 2007, the 60th World Health Assembly endorsed the Global Plan of Action on Workers' Health (GPA), 2008-2017 and set clear objectives and priority areas for action, one of which was to protect and promote health at the workplace (3). The Stresa Declaration on Workers' Health (2006), the ILO Promotional Framework for Occupational Health and Safety Convention (ILO Convention 187) (2006), and the Bangkok Charter for Health Promotion in a Globalized World (2005) also provided important points of orientation for linking occupational health with public health to achieve a basic level of health for all workers (2).

In this context, the WHO provided a flexible framework Healthy Workplaces: A Model for Action (2010), which was adaptable to diverse countries, workplaces, and culture (4). At the core of the model is the need to secure the engagement of the workforce via effective leadership and the promotion of workplace culture values that underpin health and wellbeing by considering 4 action areas including the following: 1) the physical work environment; 2) the psychosocial work environment; 3) personal health resources; and 4) enterprise involvement in the community. Since then, numerous groups and networks addressing workplace health have been developed in different regions and countries. The European Network for Workplace Health Promotion provided the definition of "Workplace Health Promotion (WHP)" as "the combined efforts of employees, employers, and society to improve the health and wellbeing of people at work" (5). The "Healthy Enterprise" Standard (BNQ9700$800)$ in Canada specified a series of WHP action plans and recognized the efforts of companies by certifying them to maintain and sustainably improve the health of people in the workplace (G). The Total Worker Health approach in the United States was defined as policies, programs, and practices that integrated 
protection from work-related safety and health hazards with promotion of injury and illness-prevention efforts to advance the wellbeing of the United States workforce (7). The Total Health Promotion in Japan was a groundbreaking approach to health promotion theory and practice and aimed to enhance the human experience free from restrictive classifications and false images (8).

Since 1993, pilot projects for workplace health practice in different industries and companies have been developed with the support of the WHO. The project has explored and summarized overall intervention strategies of WHP that were verified effectively and suitable in China (9). A series of WHP practical tools, including the compilation of regulations, archives, evaluation tools, typical cases, analyses, and health education resources, etc., have been developed for the implementation, assessment, and evaluation of healthy enterprises. Although enormous practices and achievements have been made, numerous problems, including lack of recognition of the importance of occupational disease prevention, inadequate capacity of occupational health services and little funding, have constrained further development of WHP in China. In October 2019, "Healthy Enterprise" Action Plan (HEAP) was issued nationwide with the aim of providing new impetus to move from strategy to action and to shift the pilot exploration to a practical and indispensable part of "Healthy China" and "Healthy City". Recently, experts of China CDC, together with experts of government agencies and other stakeholders, have jointly developed a practical guideline specific for various enterprises, standardizing the following 4 major advocacy action indicators, as listed in Table 1.

\section{MAJOR ACTION INDICATORS AND STRATEGIES OF HEAP}

\section{1) Establishing and Improving Health Policy Systems}

The HEAP was jointly formulated and published by
7 ministries and commissions of the central government, and a multi-sectoral cooperation mechanism in which each department promotes workers' health collaboratively, and a leading group of national health enterprise construction were established. In line with the administrative impetus provided by the Chinese government to put health in top priority for all policies, policy instruments and mechanisms on workers' health based on the needs identified at the enterprise level must be developed and implemented.

The strategy of HEAP advocates that all components of health systems should be involved in an integrated response to the specific health needs of working populations, particularly the most vulnerable populations, including complying with all legal rules and regulations regarding workplace conditions; raising awareness and introducing more strict regulations, policies, work plans, and systems for controlling and preventing occupational risks in the workplace; and improving abilities of early examination, diagnosis, and treatment of occupational diseases. Furthermore, activities related to workers' health should be planned, implemented, and evaluated. Workers must be responsible for their own health and have a right to be involved at all levels in formulating, supervising, and implementing policies and programs for the establishment and development of healthy enterprises.

\section{2) Building Healthy Working Environments}

Recent data from the ILO indicated that the number of work-related deaths increased from 2.33 million in 2014 to 2.78 million in 2017 (10). A total of 18 occupational risk factors were measured in the Global Burden of Disease Survey 2016. Only occupational exposure to asbestos decreased, whereas all other exposures increased almost $7 \%$ between 1990 and 2016 (11). The National Occupational Disease Reporting System noted a total of 23,476 new cases of occupational disease in 2018 (12). One occupational disease, pneumoconiosis, is caused by exposure to dust in the workplace and accounted for more than $83 \%$ of all the occupational diseases. The report noted

TABLE 1. Major advocacy indicators proposed by the Healthy Enterprise Action Plan.

\begin{tabular}{|c|c|}
\hline Action indicators & Major contents \\
\hline $\begin{array}{l}\text { 1. Developing health policy } \\
\text { systems }\end{array}$ & $\begin{array}{l}\text { Refers to relevant organizations, staffing, funding, and policies; contracts; work injury insurances; and } \\
\text { ensuring all staff participation. }\end{array}$ \\
\hline $\begin{array}{l}\text { 2. Building healthy working } \\
\text { environments }\end{array}$ & Including general public area environments; office environments; and the production environments. \\
\hline 3. Providing health services & $\begin{array}{l}\text { Refers to general health services (e.g., infectious control, major foodborne diseases control, and regular } \\
\text { health check-up especially for female workers); mental health services; and occupational health services. }\end{array}$ \\
\hline 4. Creating healthy culture & $\begin{array}{l}\text { Refers to workplace health promotion; the psychosocial work environment; and social responsibility of } \\
\text { enterprises. }\end{array}$ \\
\hline
\end{tabular}


relatively new occupational diseases, such as mental and musculoskeletal disorders, to be on the rise. These findings suggested that technological and social changes, along with global economic conditions, were aggravating existing health hazards and creating new issues. In addition, occupational exposure to traditional and well-known risk factors are continuing to increase to a significant degree, and there is still a long way to go before the exposure to occupational risk factors reverses on a global level.

As awareness increases, more urgent and vigorous action is needed to identify the extent of the challenge of occupational diseases and prevent them from taking their toll. HEAP advocates that employers have the primary responsibility to prevent occupational diseases by taking preventive and protective measures through anticipation, recognition, evaluation, and control of risks at work. They need to combine these actions with health surveillance to detect health impacts as early as possible and identify occupational diseases with long incubation periods. In addition, they need to make sure that workplaces are as clean, hygienic, environmentally sound, comfortable, beautiful, and humane as possible.

\section{3) Improving the Performance of and Access to Health Services}

Scientific evidence has shown that, in the long term, work-related stress can lead to musculoskeletal disorders, hypertension, and cardiovascular disease. It may also alter immune function, which in turn may facilitate the development of cancer. Work-related stress can lead indirectly to problems inside and outside the workplace. Many harmful effects of lifestyle behaviors, such as smoking, alcohol and drug abuse, malnutrition, and lack of exercise, may interact with workplace hazards (13). However, adjusting the content of occupational health services may contribute to the early detection of occupational and noncommunicable diseases, and with appropriate early treatment can decrease mortality and the frequency and extent of disability.

As the role of health services in the Healthy China 2030 (14) blueprint is in the transition from basic disease treatment to prevention and health promotion, the strategies of HEAP focus on a new occupational health service paradigm that extends the classical focus on "health risk management," which is workplace hazards and risk to health, including the medical aspects of sickness, absence, and rehabilitation; the support and management of chronic noncommunicable diseases; and the WHP. Employee health programs are encouraged to assist workers to manage their occupational health, prevent chronic diseases, establish healthy behaviors, and become proactive with their healthcare, especially in relation to stress, alcohol and drugs, tobacco, nutrition, and physical activities. Companies dominated by young and middle-aged workers should pay special attention to their workers' mental health and provide psychological health services, such as employee assistance programs.

\section{4) Creating Healthy Culture}

The organizational culture refers to the attitudes, values, beliefs, and practices that are demonstrated daily in the enterprise, which affects the mental and physical wellbeing of employees. A successful enterprise is based on people working in it and on its organizational culture. A supportive workplace culture is the foundation of a healthy workplace environment. Workers in a safe and supportive environment feel better and are healthier, which in turn leads to decreased absenteeism, enhanced motivation, improved productivity, and promoted positive images of their enterprise.

The HEAP strategy, embodied in the prevention of occupational accidents and diseases, the promotion of a healthy work life, and building a culture of prevention, is a shared responsibility of employers and workers. The establishment of health culture requires social dialogue between workers' and employers' organizations, increased knowledge sharing, and adequate resources. In addition, social support from colleagues is an important determinant of wellbeing at work. Employees should enforce zero tolerance policies for harassment, bullying, or discrimination in the workplace.

\section{CONCLUSION}

The Healthy China 2030 Plan clearly outlines indicators and roadmaps to protect workers' health, and a series of national action plans to prevent and control occupational diseases and protect workers' health have recently been implemented, including Occupational Health Protection Campaign of Healthy China Initiative (2019-2030), Action Plan for Prevention and Control of Pneumoconiosis and HEAP (15). Therefore, the HEAP, consistent with international practices and the WHO's healthy workplace model, is an independent but not isolated campaign with emphasis on integrating considerable resources from governments, employers, workers, and 
other stakeholders to promote a healthy lifestyle and continuously improve healthy conditions for workers. It is an occupational practice shifting from a "labor approach" to a "public health approach" and is important to build a preventive public health culture in the context of the Healthy China Initiative.

doi: $10.46234 / \mathrm{ccdcw} 2021.095$

\# Corresponding author: Jun Ren, renjun@niohp.chinacdc.cn.

${ }^{1}$ National Institute of Occupational Health and Poison Control,
Chinese Center for Disease Control and Prevention, Beijing, China.

Submitted: January 01, 2021; Accepted: January 21, 2021

\section{REFERENCES}

1. WHO. Global strategy on occupational health for all: the way to health at work. https://www.who.int/occupational_health/globstrategy/en/. [2020-9-3].

2. WHO, Burton J. WHO healthy workplace framework and model: background and supporting literature and practices. World Health Organization, 2010. https://apps.who.int/iris/handle/10665/113144. [2020-9-3].

3. WHO. Workers' health: global plan of action. https://www.who. int/occupational_health/publications/global_plan/en/. [2020-9-3].

4. WHO. Healthy workplaces: a model for action for employers, workers, policy-makers and practitioners. https://www.who.int/occupational_ health/5_keys_EN_web.pdf?ua=1. [2020-9-3].

5. Iwanowicz E. The 19th meeting for the working group of the European network for workplace health promotion, July 1-2, 2005, Bratislawa, Slovakia. Med Pr 2005;56(5): 419-21. http://med.wanfangdata.com.
cn/Paper/Detail/PeriodicalPaper_PM16483014.

6. Canada. The "Healthy Enterprise" Standard (BNQ9700-800). https:// www.bnq.qc.ca/en/standardization/health-at-work/healthy-enterprise. html. [2020-9-3].

7. Schill AL, Chosewood LC. The NIOSH Total Worker Health ${ }^{\mathrm{TM}}$ program: an overview. J Occup Environ Med 2013;55(12):S8 - 11. http://dx.doi.org/10.1097/JOM.0000000000000037.

8. David Seedhouse. TOTALHEALTH PROMOTION mental health, rational fields and the quest for autonomy. https://hshe-soh.iums. ac.ir/files/hshe-soh/files/TOTALHEALTHPROMOTION1(1).pdf. [2020-9-3].

9. Li S, Li T, Li CL, Wang C. Intervention strategies for the national project of workplace health promotion in China. Biomed Environ Sci 2015;28(5):396 - 400. http://dx.doi.org/10.3967/bes2015.056.

10. ILO. Safety and Health at the heart of the Future of Work: Building on 100 years of experience. 2019. https://www.ilo.org/tokyo/WCMS_ 686645/lang--en/index.htm. [2019-4-15].

11. GBD 2016 Risk Factors Collaborators. Global, regional, and national comparative risk assessment of 84 behavioural, environmental and occupational, and metabolic risks or clusters of risks, 1990-2016: a systematic analysis for the Global Burden of Disease Study 2016. Lancet 2017;390(10100):1345 - 422. http://dx.doi.org/10.1016/S0140-6736 (17)32366-8.

12. China CDC. National Occupational Disease Report 2018. http://niohp. chinacdc.cn/sndt/201905/t20190531_202989.htm. [2020-9-3]. (In Chinese).

13. ILO. Working conditions in a global perspective. 2019. https://www.ilo. org/global/publications/books/WCMS_696174/lang--en/index.htm. [2019-5-6].

14. Healthy China Initiative Promotion Committee. Healthy China initiative (2019-2030). http://www.nhc.gov.cn/guihuaxxs/s3585u/ 201907/e9275fb95d5b4295be8308415d4cd1b2.shtml. [2020-9-3]. (In Chinese).

15. Xin Sun. Perspectives: steps forward to improve occupational health-China. China CDC Wkly 2020;2(18):310 - 3. http://dx. doi.org/10.46234/ccdcw2020.079. 